\title{
Framing Indigenous Leadership
}

\author{
Joseph E. Long \\ University of Charleston
}

\begin{abstract}
The concept of framing is critical to the study of leadership and sensemaking across organizations. This paper examines framing from the unique military context of American Special Forces leading indigenous people of developing countries in combat. Specifically, I identify several deficiencies in the extant leadership literature that remains insufficient for understanding the unique context of indigenous leadership. I explain how the process of framing helps with sensemaking for both American and indigenous forces to include how framing can be understood as a vehicle for conserving, generating and transforming current indigenous leadership practices. I conclude with a theoretical framing construct that suggests how framing indigenous leadership using follower-centric models can help transform American leadership into micro-level social movements capable of creating collective identity.
\end{abstract}

Keywords: framing, leadership, collective identity, social movement

\section{FRAMING INDIGEOUS LEADERSHIP}

The context of leadership is a unique aspect to a variety of leadership subfields, yet leadership is thought to be a historical construct that is observed in human interaction across time (Hartley \& Benington, 2011). This observation suggests that leadership styles and processes that determine leader effectiveness should vary across subfields according to how leaders "imagine, shape, and leverage context to accomplish organizational sustainment" (DEL 720 Syllabus, p. 2). For large organizations, leaders must be able to communicate a unifying vision to an audience of multiple stakeholders with varying organizational perspectives in order for followers to make sense of their roles in the larger picture. Maitlis and Christianson (2014) identify this process as "sensemaking" whereby "people work to understand issues or events that are novel, ambitious, confusing, or in some other way violate expectations" (Maitlis \& Christianson, 2014, p. 57). Thus, the concept of framing provides a useful method for leaders to communicate a unifying vision across multiple aspects of identity (Gardner, 2011).

Gardner (2011) uses identity to explain leadership as "a process that occurs within the minds of individuals who live in a culture" (p. 21). Gardner further hones in on culture as part of how people observe groups and develop biases for and against both in and out-groups (p. 22). These biases contribute to the overall development of individual and group identity resulting from varying development of a person's cognitive ability from the five-year-old mind through to the adult expert (p. 28). Since people develop their identity differently, frames become useful tools for leaders to understand social identity so that vision is "framed in a way that highlights its compatibility with ingroup prototypes" (Seyranian, 2014, p. 469). Furthermore, scholars identify framing as part of social movements which contributes to collective action (Olson, 1965; Polletta \& Jasper, 2001; Tarrow, 1994). Tarrow (1994) describes "framing work" as part of the process where "cultural frames lower the costs of bringing people together in collective action" (p. 23). Thus, an understanding of framing and culture is a useful tool for leaders to create collective identity and drive collective action in terms useful to large organizations with varying perspectives. 
To better understand how framing affects sensemaking across organizations and contributes to effective leadership, this paper will examine framing from the unique military context of American military forces leading indigenous people of developing countries in combat. Specifically, I will explain how extant leadership literature remains insufficient for understanding the unique context of indigenous leadership, and then explain how the process of framing helps with sensemaking for both American and indigenous forces, to include how framing can be understood as a vehicle for conserving, generating and transforming current indigenous leadership practices. Furthermore, I conclude with a theoretical framing construct that suggests how framing indigenous leadership using follower-centric models can help transform American leadership into micro-level social movements capable of creating collective identity.

\section{EXTANT LITERATURE}

Leadership literature is broad and defines multiple theories that could shape or inform the inherent challenges of indigenous leadership. However, upon close inspection of the extant theories, it becomes clear that a unified theory of indigenous combat military leadership is both necessary and absent from the literature. For the purposes of this paper, the development of indigenous leadership is related to the mission of the United States (US) Army Special Forces (SF) Regiment which exists to conduct special operations across the range of military operations to "disrupt or eliminate threats unilaterally, with partners or friendly indigenous forces" (Army Doctrine Publication 3-05: Special operations, 2012, p. 7). Specifically, special warfare is the "execution of activities that involve a combination of lethal and nonlethal actions taken by a specially trained and educated force that has a deep understanding of cultures and foreign language, proficiency in small-unit tactics, and the ability to build a fight alongside indigenous combat formations in a permissive, uncertain, or hostile environment" (p. 9).

As a function of indigenous leadership, unconventional warfare, the primary mission of SF, includes "activates conducted to enable a resistance movement or insurgency to coerce, disrupt, or overthrow a government or occupying power by operating through or with an underground, auxiliary, and guerrilla force...to influence the indigenous population to support the resistance movement or insurgency" (p. 9). With the specific challenges of American SF forces in mind, the following review of extant literature will underscore the absence of sufficient literature to explain indigenous leadership in the context of American Special Forces.

From a Clausewitzian perspective, the relationship between a states' political concerns and military actions are thought to be an extension of the former (Clausewitz, 1989). However, in Hartley and Benington's (2011) discussion of political leadership, the connection between political desires and indigenous leadership is not addressed. With political leadership defined as the "reciprocal process of mobilizing, by persons with certain motives and values, various economic, political, and other resources, in a context of competition and conflict," Hartley and Bennington validate the political connection between interstate politics and military operations, but fail to provide the micro-level detail necessary to explain the challenges of developing and conducting indigenous military operations (Hartley \& Benington, 2011, p. 203).

Likewise, Hansen and Bathurst (2011) explain aesthetic leadership and how symbolism and emotion contribute to notions of emancipation and revolution (Hansen \& Bathurst, 2011). In discussing the difference between "power-with" versus "power-over" organizations, Hansen and Bathurst suggest the potential for American forces to employ indigenous forces in a power struggle against a rival state in discussing "vehicles of liberation" (p. 261). This process 
addresses the political premise of UW in "freeing individuals and groups from repressive social and ideological conditions, in particular, those which constrain human development" (p. 259). Although liberation is addressed in the aesthetic leadership tradition, the liberation idea is never fully developed. Specifically, the American military experience in Vietnam, Afghanistan, and Iraq suggest the potential for military operations oriented toward liberation to come with a hidden "liberator's dilemma" where responsibility for a population inherently transfers from the original governing body to the liberating military forces. Therefore, Hansen and Bathhurst are only partially helpful in understanding the dynamic of indigenous military leadership.

In addition to the political context of leadership, other scholars address leadership challenges from various cross-cultural perspectives. Guthey and Jackson (2011) address cross-cultural leadership from an international business standpoint, but fail to capture the nuances necessary to explain cross-cultural leadership in the UW context. Guthey and Jackson's models are limited to explaining business leadership relationships and remain fixed at understanding nationallevel cultural leadership problems (Guthey \& Jackson, 2011). Additionally, cross-cultural leadership fails to address the paramilitary aspect of UW-oriented leadership and the quality of local culture often observed in tribal traditions that make micro-cultural understanding critical for leading indigenous forces.

Furthering the cross-cultural problems of leadership, Collinson (2011) explains a weakness of Western-oriented leadership in being rooted in the "cultural history of mythical heroes," (Collinson, 2011, p. 183) while Case, et al. (2011) suggest that Western leaders are overly representative of the "Stereotype of the white middle-class male" (Case, French, \& Simpson, 2011, p. 243). This suggests that much of the literature in leadership behavior might fail to resonate in the context of indigenous leadership since UW operations are most likely to occur in underdeveloped and largely tribal societies where cultural identity remains limited to the local level. In such cases, the suggestions of leadership behavior presented in the scholarly literature are less likely to remain relevant to the indigenous leadership context.

Historical and behavioral aspects of leadership, which make up the lion's share of leadership literature, remain incapable of defining the leadership challenges of indigenous leadership. From a historical perspective, Grint (2011) explains how military operations and warfare served as the earliest forms of leadership practice and how such practice was eventually adapted for the fundamentals of political and business leadership styles. Similarly, Porter (1994) furthers the military perspective of leadership in explaining how the skills needed in leading armies in warfare contribute to development in other areas (Grint, 2011; Porter, 1994).

From a behavior preference perspective, some scholars identify specific personality and behavioral traits that are thought to contribute to effective leadership. Conger (2011) describes the benefits of a charismatic personality in producing effective leadership results, while Caza \& Jackson (2011) suggest that authentic leadership is critical to creating follower loyalty (Caza \& Jackson, 2011). Perhaps the most popular behavioral trait found in leadership literature is transformational leadership which is characterized by "a strong emotional attachment" and high "collective commitment to a higher moral cause" (Díaz-Sáenz, 2011, p. 299).

Despite the breadth of leadership literature, the cross-cultural implications of indigenous leadership suggest that connecting Western military forces with developing indigenous forces is problematic. Not only does the literature of behavior preferences remain limited to the 
context of Western culture, the psychological perspectives outlined in attachment theory remain equally difficult to apply in the UW context. The mismatch of American and indigenous forces will only decrease the ability for "relational experiences with significant others, including parents, friends and romantic partners, especially in times of distress" to contribute to developing mutual attachment (Game, 2011, p. 327).

\section{Framing}

Despite the foreseeable challenges observed in indigenous leadership, the literature of framing provides the necessary vehicle to enhance sensemaking between American and indigenous forces where both can develop a shared social identity (Seyranian, 2014). Therefore, an understanding of framing literature is critical to understanding potential resolutions to the indigenous leadership problem. Although framing is often observed as critical to social movements, the realities of indigenous leadership at the micro-level suggest that framing many of the critical issues related to identity, culture, and learning are also derived from the collective action found in successful social movements. Thus, framing indigenous leadership as building a joint social movement should be useful in overcoming many of the theoretical gaps and problems previously identified in the review of the extant literature.

In understanding framing from an indigenous context, it is useful to understand how messaging resonates across cultural divides. According to Yu and Shen (2013), message frames oriented toward collective action are more effective when "culturally tailored" to the necessary degrees of individualism and collectivism of the culture (Yu \& Shen, 2013, p. 133). The authors identify how message frames resonate differently in individualist versus collectivist cultures regarding preventative health issues. Specifically, they find strong empirical evidence that citizens in Hong Kong are more likely to get a flu shot in response to a collective health frame than one oriented toward individualist concerns, while the opposite is true for messaging in America. This observation suggests how American leaders can shape framing efforts to improve calls to action through tailored message framing. Specifically, Yu and Shen indicate that messages which successfully resonate as a call to action for Americans might not work in indigenous cultures. As an example, the framing of the conflict in Afghanistan is an appeal to countering terrorism in a way that appeals to the American sense of justice, but such framing resonates very little in capturing the long-term support of many decentralized Afghan tribal populations.

Framing can also enhance the understanding of many cross-cultural aspects of leadership. Galander (2012) examines how media framing of Islamic-oriented conflicts can impact support from indigenous Islamic populations by uncovering how media framing of Islamic conflicts by the New York Times perpetuate negative stereotypes of Islamic culture (Galander, 2012). With Western media outpacing Islamic media, the negative framing of Islam is shown to minimize the desire for the West to provide military aid in Darfur. Thus, in the context of indigenous leadership, such framing issues not only incentivize indigenous forces to avoid interacting with Western powers, the media framing also negatively impacts the West's views of why military intervention is important. Thus, in terms of trust, American forces must understand the effect of the media and present their leadership goals in a manner that counters prominent negative media frames of anti-Islamic bias (Kramer, 2011; Kydd, 2000).

Similarly, Taha (2012) also examines anti-Islamic media frames and finds that Western media bias also negatively frames Africans and Arabs, which negatively impacts the American forces' ability to establish cross-cultural trust. As Kramer (2011) explains, the impact of negative media framing makes building trust with indigenous forces difficult given the prominence of 
American media frames. As social movement theory suggests, the media can "mobilize a following" and affect the degree to which tribal forces of developing countries will accept American framing of political objectives between US and indigenous forces and thus respond to American attempts at paramilitary leadership.

In terms of leader emergence, Ho et al. (2012) observe the effect of task framing on responsiveness in mixed-gender dyads. Just as males respond better to tasks framed as masculine and females responded to tasks framed as feminine, the potential for similar framing distinctions to affect American and indigenous audiences remains prominent (Ho, Shih, \& Walters, 2012). By understanding the framing effect that labels have on emergent leaders, similar framing efforts should be considered for leaders of indigenous forces. This observation validates the need for Western leaders of indigenous forces to carefully consider the framing impacts of how the media communicates the conflict and how media framing might negatively impact the attitudes and behavior of people at the micro-level who will serve as indigenous forces. As an example, media framing of the Afghan conflict in 2011 was that the war was over and that the US was likely to pull out all forces by 2012. In response, the indigenous forces that were supported by the American military were likewise affects by news reports and suffered commitment problems relative to an unanticipated US withdrawal of military support in the fight against the Taliban (Fearon, 1994b). Such negative framing can result in unanticipated audience costs that reduce trust and increase tension between forces reliant on long-term American support and create a reputation where the US continues to make false promises (Fearon, 1994a).

Adding to the problems with media framing, cross-cultural differences are also problematic in dealing with conflict. Brett et al. (2014) note that cultures respond differently to direct versus indirect conflict and that motivations can be framed to better incentivize action (Brett, Behfar, \& Sanchez-Burks, 2014). Specifically, they find that direct confrontation in Western cultures appeals to more substantive and reason-based issues, while non-Western cultures respond better to relational concepts and emotional notions of preserving harmony and integrating interests (p. 143). Such an approach typifies the American approach to leadership of "focus on reason over emotion along a prevailing ideology that defines professionalism in terms of maintaining a polite impersonal approach" which can be harsh on a culture that prefers indirect confrontation styles (p. 143). In such cases, American forces can use framing concepts to shape the indigenous understanding of the joint organization at the micro-level as a vehicle for returning harmony to the people at the local level. By framing the conflict in an indirect style and shifting the motivation frame away from direct conflict, American forces can avoid many of the cultural and behavior roadblocks described in the literature.

Unfortunately, many motivational frames that are prominent in Western culture and observed in Western leadership literature are difficult to employ in the context of indigenous leadership. Specifically, Maitlis and Christianson (2014) note how emergency situations can provide a unifying frame that defines problems across multiple organizations and incentivizes the formation of temporary organizations motivated for action (Maitlis \& Christianson, 2014, p. 86). Fortunately, framing literature provides examples of conflict where direct and indirect frames can affect cross-cultural audiences differently. However, as with Western-style behavioral preferences, the ability for US forces to frame emergencies is negatively affected by Western media framing and American bias. Although ad hoc organizations can form and work together in the Western context, creating a shared sense of emergency can be problematic in an indigenous context. This observation is particularly salient considering that the 
environment that American forces enter into militarily is the default status quo for the indigenous people. Thus, the ability to stir emotion in establishing an emergency frame can be inherently difficult.

Despite the problems with creating a shared state of emergency, social identity framing can provide American leaders with improved possibilities for framing a unified identify between American and indigenous forces (Seyranian, 2014). This process of accomplishing identity development requires three critical steps: "unfreezing the groups from the present level, changing or moving the group to a new level, and refreezing the group on that level" (p. 470). However, identity formation is not without challenges as identity framing assumes that prototypicality in leadership is correlated with increased homogeneity and improved leadership performance (p. 472). For the context of UW and the prominence of heroic leader archetypes in Western culture, American military forces are unlikely to fit in as prototypical leaders from the indigenous perspectives.

Additionally, Seyranian (2014) notes that the use of inclusive language is critical to identity freezing by creating an emotional connection between leaders and followers (p. 473). However, such a concept is problematic for American forces since the degree of being a prototypical leader affects the necessary conditions for framing "policies, stereotypes, norms, attitudes, values, group attributes, behavioral intentions" that are essential in generating rhetoric that shapes identity (p. 472). Although Seyranian suggests that charismatic leadership styles are effective under these conditions, the ability for American forces to present effective charismatic influence at the micro-level cross-cultural setting makes identity framing increasingly difficult. Furthermore, the method suggested for developing shared identity is the use of inclusionary language that expresses group satisfaction, shared values, and commonality of attributes. For Americans working with mostly tribal cultures of developing countries, finding effective inclusionary language to frame joint identity can be problematic in the UW context. However, the structure of special operations includes units who might be helpful in identifying language that enables a UW practitioner to build a shared identity.

In addition to shared identity, framing identity is observed by Haas (1992) who notes that American and indigenous forces are affected by diverging "socially constructed realities" that impact the degree to which cross-cultural allies might fully support one another (Haas, 1992, p. 18). Likewise, leadership literature also explains the effect of motivated reasoning and the tendency to remain biased when facing contradictory information (Lord, Ross, \& Lepper, 1979). This suggests that reframing or counter framing forces that are previously biased by media frames against Islamic or Arabic people as explained by Taha (2012) exceedingly difficult. In fact, Lord et al. (1979) and Ditto and Lopez (1992) both suggest that preexisting biases in indigenous cultures could create polarization during UW efforts as American efforts to counter preexisting media frames can be considered "inconsistent feedback" and "perceived as less valid, less accurate” (Ditto \& Lopez, 1992, p. 569).

However, from a positive perspective, Chong and Druckman (2013) note that "the relative timing of competing messages and the repetition of counter-frames" impact the indigenous desire to work with American forces (Chong \& Druckman, 2013, p. 3). Furthermore, counterframing literature suggests ways that Americans can reframe problems with previously absorbed negative frames in indigenous populations, as the nature of indigenous leadership makes such counter-framing inherently difficult. As an example, counter-framing literature suggests that time plays a role in allowing counter-framing efforts to become influential as "extending the time lag between frame and counter-frame can increase the impact of the 
counter-frame by allowing initially strong opinions to decay" (p. 1). However, for a small force of American SF forces in a hostile situation, the luxury of time might not be available, suggesting the need for alternative sources of counter-framing assistance that might mitigate the need for time in a constrained environment.

To better understand ways that American forces can frame indigenous leadership in a UW context, SF units are assisted by psychological operations (PSYOP) units who use framing and counter-framing techniques to influence "the most appropriate foreign target audiences to elicit behaviors favorable to U.S. national objectives" (Department of the Army Field Manual 305.301 Psychological operations process tactics, techniques, and procedures, 2007, p. viii). To accomplish this, PSYOP units conduct military operations to target various "foreign audiences to influence their emotions, motives, objective reasoning, and ultimately the behavior of foreign governments, organizations, groups, and individuals" (p. 1-8). Although this definition typically applies to enemy formations and population-centric demographics, the analysis and capability of PSYOP remain equally capable of reframing American attempts at indigenous leadership contextually to shape joint US/indigenous units as micro-level social movements with shared identity and collective action (Tarrow, 1994).

\section{CONCLUSION}

Understanding the micro-level culture of an indigenous military force requires significant and specific skills that fall outside of the prototypical Western leadership approach common to American military leaders. Specifically, understanding the role that framing and counterframing play in shaping the context of leadership becomes useful to understanding the indigenous audience. Furthermore, as an essential part of social movement theory, strategic framing can help American forces use the context of a micro-social movement to establish collective identity (Tarrow, 1994). However, the extant literature on indigenous leadership implies the need for a unique leadership frame that helps steer American forces away from the heroic leader archetype. With the literature of framing in mind, the use of follower-centric leadership models can transform indigenous leadership into micro-level social movements and create the necessary collective identity needed to foster leadership and collective action.

Bligh's (2011) work on follower-centric approaches to leadership remains reminiscent that "the essence of leadership is followership" and suggests a unique theoretical approach to indigenous leadership (Bligh, 2011, p. 425). The follower-centric approach to leadership challenges the Western leadership ideal of leaders and followers as "roles, not people," with followers who are "active, not passive," and who must share the same united purpose. From the social movement perspective, framing American leadership attempts as follower-centric can overcome many of the prominent negative traits of Western leadership models and provide a vehicle for achieving collective identity.

Likewise, the follower-centric approach can help American Soldiers escape the romantic notion that leaders are "inherently positive forces for individuals, organizations, and humanity as a whole" (p. 428), and the accompanying Western confrontational leadership style (Brett et al., 2014 , p. 143) which creates an indigenous leadership paradox. For elite American SF Soldiers, the degree to which such leaders are suited to lead other American forces is the same degree to which the same leaders are not suited to lead indigenous forces. Based on this paradox, it follows that SF Soldiers must become proficient in both Western and other alternative approaches. 
To provide the necessary guidance for developing a secondary leadership style, Bligh (2011) builds on Howell and Mendez (2008) to offer three perspectives on the follower-centric approach to leadership that includes being interactive, independent, and shifting so that the "followers complement and support the leader...as critically important to achieving team and organizational goals as the leadership process " (p. 429). By understanding and utilizing these principles when engaging in military operations involving indigenous forces, the UW practitioner increases the potential for success.

Unfortunately, the current model for training SF Soldiers to lead indigenous forces remains systematically flawed in its approach.

The exercise that exposes SF students to indigenous leadership is known as "Robin Sage" and represents the culminating exercise (CULEX) for future SF Soldiers to meet, train, and lead indigenous role players in a simulated UW environment that takes place year-round in Central North Carolina. On a positive note, Robin Sage training provides realistic and effective training on the systematic and organizational dynamics of UW and allows students to explore the capabilities and tactics involved in working with guerilla, underground, and auxiliary facets of an insurgency (Department of the Army Field Manual 3-05.130 Army Special Operations Forces Unconventional Warfare, 2008).

However, the Robin Sage CULEX suffers from logistical constraints in providing realistic role players to simulate the indigenous leadership experience. This limitation is usually solved by allowing beginner SF students to function as guerilla forces under the leadership of a more senior (usually a retired senior SF Soldier) guerilla leader (G-Chief). As such, the G-Chief can provide realistic scenarios for SF students and mimic many of the hardships that come with UW, but the G-Chief and the guerilla forces are unlikely to realistically mimic the leadership style needed for SF students to lead real indigenous forces.

In conclusion, the indigenous leadership paradox coupled with the training limitations of SF Soldiers underscore the need for American forces to understand and reframe the downsides of the prototypical Western leadership model. Based on extant leadership literature, current models remain insufficient for understanding the contextual dynamics of indigenous leadership. The process of framing indigenous leadership provides the necessary starting point for overcoming the leadership paradox and the problematic relationship between suitable leadership models for Western versus indigenous audiences. By reframing indigenous leadership in follower-centric terms, SF Soldiers should be able to establish the necessary collective identity thought to drive collective action as a joint combat unit. Future research could investigate the connection between joint identity and performance to provide imperial support to the above hypothesis.

\section{References}

Army Doctrine Publication 3-05: Special operations. (2012). Washington, DC: Headquarters, Department of the Army.

Bligh, M. C. (2011). Followership and follower-centered approaches. In A. Bryman, D. Collinson, K. Grint, B. Jackson, \& M. Uhl-Bien (Eds.), The SAGE handbook of leadership (pp. 425-436). Thousand Oaks, CA: Sage.

Brett, J., Behfar, K., \& Sanchez-Burks, J. (2014). 9. Managing cross-culture conflicts: A close look at the implication of direct versus indirect confrontation. In Handbook of Research in Conflict Management (pp. 136-154). Edward Edgar Publishing.

Case, P., French, R., \& Simpson, P. (2011). Philosophy of leadership. In A. Bryman, D. Collinson, K. Grint, B. Jackson, \& M. Uhl-Bien (Eds.), The SAGE handbook of leadership (pp. 242-254). Thousand Oaks, CA: Sage. 
Caza, A., \& Jackson, B. (2011). Authentic leadership. In A. Bryman, D. Collinson, K. Grint, B. Jackson, \& M. Uhl-Bien (Eds.), The SAGE handbook of leadership (pp. 352-364). Thousand Oaks, CA: Sage.

Chong, D., \& Druckman, J. N. (2013). Counterframing effects. Journal of Politics, 75(1), 1-16.

Clausewitz, C. V. (1989). On war. (M. Howard \& P. Paret, Eds.). Princeton University Press.

Collinson, D. (2011). Critical leadership studies. In A. Bryman, D. Collinson, K. Grint, B. Jackson, \& M. Uhl-Bien (Eds.), The SAGE handbook of leadership (pp. 181-194). Thousand Oaks, CA: Sage.

Department of the Army Field Manual 3-05.130 Army Special Operations Forces Unconventional Warfare. (2008). Washington, DC: Headquarters, Department of the Army.

Department of the Army Field Manual 3-05.301 Psychological operations process tactics, techniques, and procedures. (2007). Washington, DC: Headquarters, Department of the Army.

Díaz-Sáenz, H. R. (2011). Transformational leadership. In A. Bryman, D. Collinson, K. Grint, B. Jackson, \& M. UhlBien (Eds.), The SAGE handbook of leadership (pp. 299-310). Thousand Oaks, CA: Sage.

Ditto, P. H., \& Lopez, D. F. (1992). Motivated Skepticism: Use of differential decision criteria for preferred or nonpreferred conclusions. Journal of Personality and Social Psychology, 63(4), 568-584.

Fearon, J. D. (1994a). Domestic political audiences and the escalation of political disputes. The American Political Science Review, 88(3), 577-92.

Fearon, J. D. (1994b). Ethnic war as a commitment problem. Paper Presented at the Annual Meeting of the American Political Science Association, 1-24.

Galander, M. M. (2012). News values, cultural proximity and cross-cultural media framing: How western and Muslim media covered Darfur. Journal of Arab \& Muslim Media Research, 5(2), 113-128.

Game, A. M. (2011). Leadership and attachment theory: Understanding interpersonal dynamics in leader-follower relations. In A. Bryman, D. Collinson, K. Grint, B. Jackson, \& M. Uhl-Bien (Eds.), The SAGE handbook of leadership (pp. 326-337). Thousand Oaks, CA: Sage.

Gardner, H. (2011). Leading minds: An anatomy of leadership. New York, NY: Basic Books, Perseus Books Group.

Grint, K. (2011). A history of leadership. In A. Bryman, D. Collinson, K. Grint, B. Jackson, \& M. Uhl-Bien (Eds.), The SAGE handbook of leadership (pp. 3-28). Thousand Oaks, CA: Sage.

Guthey, E., \& Jackson, B. (2011). Cross-cultural leadership revisited. In A. Bryman, D. Collinson, K. Grint, B. Jackson, \& M. Uhl-Bien (Eds.), The SAGE handbook of leadership (pp. 165-178). Thousand Oaks, CA: Sage.

Haas, P. (1992). Epistemic Communities and International Policy Coordination. International Organization, 46(1), $1-35$.

Hansen, H., \& Bathurst, R. (2011). Aesthetics and leadership. In A. Bryman, D. Collinson, K. Grint, B. Jackson, \& M. Uhl-Bien (Eds.), The SAGE handbook of leadership (pp. 255-266). Thousand Oaks, CA: Sage.

Hartley, J., \& Benington, J. (2011). Political leadership. In A. Bryman, D. Collinson, K. Grint, B. Jackson, \& M. UhlBien (Eds.), The SAGE handbook of leadership (pp. 203-214). Thousand Oaks, CA: Sage.

Ho, G. C., Shih, M., \& Walters, D. J. (2012). Labels and leaders: The influence of framing on leadership emergence. The Leadership Quarterly, 23(5), 943-952. https://doi.org/10.1016/j.leaqua.2012.06.003

Kramer, R. M. (2011). Trust and distrust in the leadership process: A review and assessment of theory and evidence. In A. Bryman, D. Collinson, K. Grint, B. Jackson, \& M. Uhl-Bien (Eds.), The SAGE handbook of leadership (pp. 136-150). Thousand Oaks, CA: Sage.

Kydd, A. (2000). Trust, Reassurance, and Cooperation. International Organization, 54(2), 325-357.

Lord, C. G., Ross, L., \& Lepper, M. R. (1979). Biased assimilation and attitude polarization: The effects of prior theories on subsequently considered evidence. Journal of Personality and Social Psychology, 37(11), $2098-2109$.

Maitlis, S., \& Christianson, M. (2014). Sensemaking in organizations: Taking stock and moving forward. The Academy of Management Annals, 8(1), 57-125. https://doi.org/10.1080/19416520.2014.873177

Olson, M. (1965). The logic of collective action: Public goods and the theory of groups (Vol. 124). Cambridge, Mass.: Harvard University Press. 
Polletta, F., \& Jasper, J. M. (2001). Collective identity and social movements. Annual Review of Sociology, 27, 283305.

Porter, B. D. (1994). War and the rise of the state. New York: Simon \& Schuster.

Seyranian, V. (2014). Social identity framing communication strategies for mobilizing social change. The Leadership Quarterly, 25(3), 468-486. https://doi.org/10.1016/j.leaqua.2013.10.013

Tarrow, S. (1994). Power in movement: Social movements, collective action and politics. Cambridge: Cambridge University Press.

Yu, N., \& Shen, F. (2013). Benefits for me or risks for others: A cross-culture investigation of the effects of message frames and cultural appeals. Health Communication, 28(2), 133-145. 